\title{
Interpretation of Doppler effect-based vertical velocity measurements in the coastal waters of Estonia, Baltic Sea: possible influence of upwelling, Langmuir circulation and turbidity
}

\author{
Ü. Suursaar \\ Estonian Marine Institute, University of Tartu, Estonia
}

\begin{abstract}
Doppler effect-based oceanographic instruments have proved very useful in studies of the vertical structure of currents, as well as for vertical fluxes between different layers in frontal zones and upwelling. This paper describes our experiences with a Recording Doppler Current Profiler in the Estonian coastal waters in 2003-2008. The primary task of the field campaigns varied from coastal geomorphic and wave studies to measurements of upwelling-related baroclinic jets. The paper focuses mainly on vertical velocity data. Apart from the vertical structures of horizontal currents that strongly imply on upwelling, it was not possible to explain the surprisingly large $(1-2 \mathrm{~cm} / \mathrm{s})$ velocities merely by up- or downwelling. We assume that the contribution of true hydrodynamic processes is either very small or appears as "noise" due to a mismatch between the characteristic scale of a processes (e.g. Langmuir circulation) and our measurement integration. Moreover, such data largely includes the influence of particles that are not neutrally buoyant: suspended matter, gas bubbles, detritus, organisms, etc. In relatively turbid and geomorphically active parts of the Estonian coastal waters, the source of that dominant signal primarily reflects the equilibrium between resuspension and settling of mineral particles.
\end{abstract}

Keywords: RDCP, resuspension, Langmuir circulation, up- and downwelling.

\section{Introduction}

The role of vertical fluxes in the coastal marine ecosystem is rather diverse, as a large amount of energy and matter exchange between the surface and deep layers 
occurs by means of vertical flows. The upwelled water is usually rich in nutrients, and upwelling regions are among the most important fishing regions of the World Ocean. Also, in the Baltic Sea, upwelling triggers profound changes in the phytoplankton community and productivity [1,2].

In recent years, the Doppler effect-based technology of flow measurements has offered a tool, which, at least according to its principle, enables to measure the vertical structure of both horizontal and vertical velocities. Nevertheless, relatively small values to be measured and difficulties in interpretation of its sources have left direct measurement of vertical velocities controversial.

A Recording Doppler Current Profiler RDCP-600 from AADI Aanderaa Instruments was used in five case studies in the Estonian coastal waters in 20032008 (Table 1, Fig. 1). The primary tasks of these deployments varied from monitoring of influences of dredging in the Port of Muuga construction (Exp.A), study on dilution conditions of pulp mill effluents near Kunda (Exp.B,C [3]), wave studies near geomorphically active, accumulative gravel spit of Harilaid Peninsula (Exp.D [4]), and study of upwelling and coastal jets (Exp.B,E [2]). The aim of this paper is to present a statistical description of the obtained "vertical velocity" data and to interpret their origin.

\section{Study area}

The Baltic Sea is a semi-enclosed, brackish water body with a surface area of $377000 \mathrm{~km}^{2}$ and average depth of $55 \mathrm{~m}$. Estonian coastal waters (Fig. 1) are featured by relatively low (4-8) salinity, high turbidity, and high trophic status.

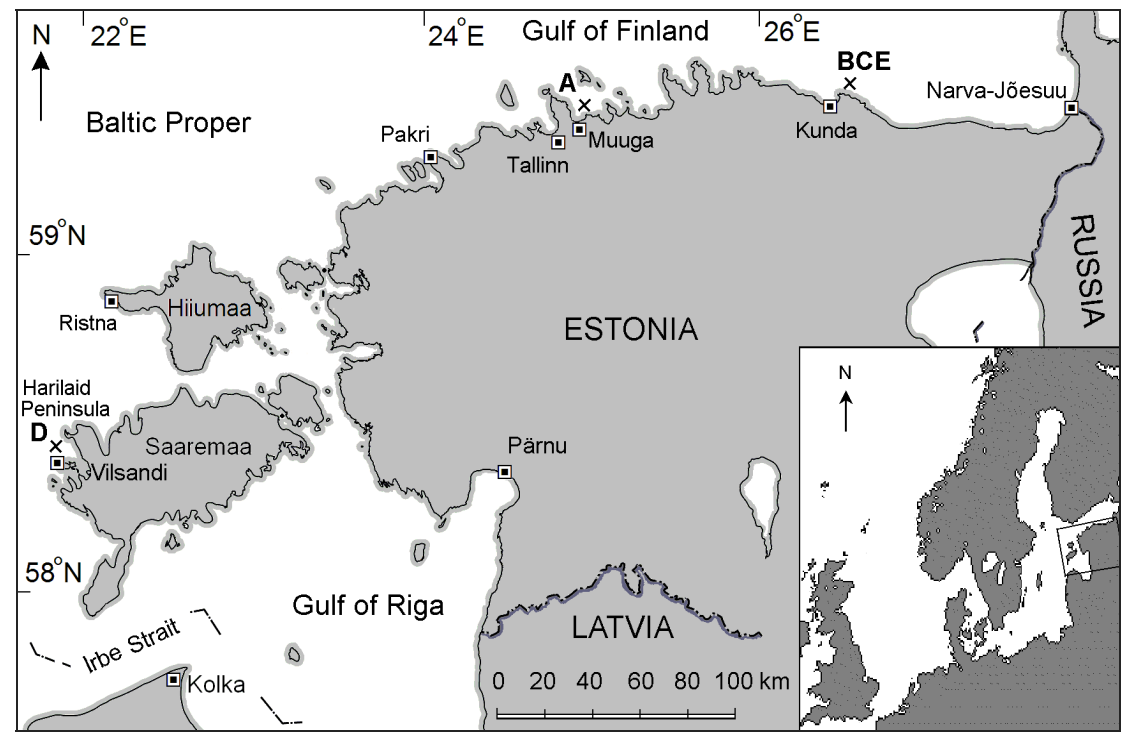

Figure 1: The study area and the RDCP-600 mooring sites near Muuga (A), Kunda (B,C,E), and Harilaid Peninsula (D); see also Table 1. 
Table 1: $\quad$ RDCP measurements in the Muuga Bay (Exp.A), near Letipea Peninsula (B,C,E), and Harilaid Peninsula (D); for the locations on the map see also Fig. 1.

\begin{tabular}{|c|c|c|c|c|c|c|c|}
\hline \multirow[t]{2}{*}{ Exp. } & \multicolumn{3}{|c|}{ Deployment } & \multirow{2}{*}{$\begin{array}{l}\text { No of } \\
\text { layers }\end{array}$} & \multirow{2}{*}{$\begin{array}{l}\text { No of } \\
\text { records }\end{array}$} & \multirow{2}{*}{$\begin{array}{c}\text { Interval } \\
\text { (min) }\end{array}$} & \multirow{2}{*}{$\begin{array}{c}\text { Duration } \\
\text { (days) }\end{array}$} \\
\hline & Period & Coordinates & Depth (m) & & & & \\
\hline $\mathrm{A}$ & $\begin{array}{l}27.10 .03- \\
05.11 .03\end{array}$ & $\begin{array}{l}59^{\circ} 30.8^{\prime} \mathrm{N} \\
25^{\circ} 00.5^{\prime} \mathrm{E}\end{array}$ & $11.5-12.0$ & 6 & 1285 & 10 & 8.9 \\
\hline $\mathrm{B}$ & \begin{tabular}{|l|}
$10.08 .06-$ \\
14.09 .06
\end{tabular} & $\begin{array}{l}59^{\circ} 33.7^{\prime} \mathrm{N} \\
26^{\circ} 40.3^{\prime} \mathrm{E}\end{array}$ & 10.9 & 6 & 5023 & 10 & 34.9 \\
\hline $\mathrm{C}$ & $\begin{array}{l}6.10 .06- \\
01.11 .06\end{array}$ & $\begin{array}{l}59^{\circ} 33.7^{\prime} \mathrm{N} \\
26^{\circ} 40.3^{\prime} \mathrm{E}\end{array}$ & 10.8 & 6 & 1179 & 20 & 16.4 \\
\hline $\mathrm{D}$ & \begin{tabular}{|l|}
$20.12 .06-$ \\
23.05 .07
\end{tabular} & $\begin{array}{l}58^{\circ} 23.0^{\prime} \mathrm{N} \\
21^{\circ} 48.9^{\prime} \mathrm{E}\end{array}$ & $13.4-14.7$ & 8 & 3691 & 60 & 153.8 \\
\hline E & $\begin{array}{l}13.08 .08- \\
17.09 .08\end{array}$ & $\begin{array}{l}59^{\circ} 33.7^{\prime} \mathrm{N} \\
26^{\circ} 40.3^{\prime} \mathrm{E}\end{array}$ & $10.4-11.0$ & 7 & 1677 & 30 & 34.8 \\
\hline
\end{tabular}

Climatologically, Estonia lies along the prolongation of the so-called North Atlantic storm track. Thus, as opposed to the negligible role of astronomic tides, the frequent passage of cyclones and the variable meteorological forcing above the sea cause considerable sea level fluctuations and highly variable wind-driven currents along the heavily indented coast [4] (Fig. 1).

\section{Material and methods}

The instruments, referred by different manufacturers as e.g. DCM (Doppler current meter), ADCP or ADV, apply the Doppler effect to measure velocity. An instrument acts both as source and receiver while bouncing short pulses (pings) of acoustic energy. The frequency of the backscattered signals (from small particles, plankton, gas bubbles, etc.) are Doppler shifted proportionally to the average radial relative velocity between the scatterers and the transducers. Four beams are simultaneously pinged with a $25^{\circ}$-slant angle in the RDCP-600 and three velocity components are calculated from the returning signals.

The self-contained upward looking instrument was deployed about 1-3 km off the coast (Fig. 1) by divers. Considering the mooring depth, a $2 \mathrm{~m}$ blanking distance between the instrument and the lowermost measurable cell, 2-3 surface meters, which measurements are "contaminated" by wave motions, $2 \mathrm{~m}$ cell size and $50 \%$ cell overlap, data from $6-8$ depth layers was obtained (Table 1). Thus, e.g. "3 m depth" actually means $2-4 \mathrm{~m}$ depth interval, and due to overlap, the data from two adjacent cells are somewhat correlated.

Each current record included an average value of 300 pings (or individual measurements). The setup used by us yielded estimated standard noise levels at as low as $0.58 \mathrm{~cm} / \mathrm{s}$ for the horizontal currents and $0.29 \mathrm{~cm} / \mathrm{s}$ for vertical currents. Doubling either the cell size or the ping length yields an improvement in noise statistics of the square root of two. The recording interval varied from 10 to $60 \mathrm{~min}$ (Table 1), but the ping activity (and hence the measurement 
integration) lasted about 2-3 minutes during each measurement cycle. In addition to current measurements, the RDCP-600 is equipped with a temperature, turbidity and conductivity (i.e. salinity-) sensor, as well as the high accuracy quartz based pressure sensor, which enables to measure the relative sea level variations and wave parameters.

Data output also includes time series of signal strength, standard deviations of each beam, and information about the instrument condition (e.g. direction, pitch, roll). A beam compensation system compensates for instrument tilt and provides a true horizontal current reading even when the instrument is occasionally not positioned strictly vertically.

\section{Results and discussion}

\subsection{Statistical properties of the data}

The vertical velocity data were nearly normally distributed with averages ranging from -0.7 to $1.5 \mathrm{~cm} / \mathrm{s}$ and standard deviations $0.6-1.1 \mathrm{~cm} / \mathrm{s}$ (Fig. 2). In upper layers, either the upward velocities were smaller or downward velocities were larger than in lower layers (Fig. 3a). I.e., in lower layers, the fluxes were always more up-oriented, which also appeared from integral velocity graphs (Fig. 4): the graph for bottom layer was always the uppermost, followed by middle and nearsurface velocities. Differently from horizontal velocity components, the time series for vertical velocities looked very noisy with seemingly limited useful information (Fig. 5).

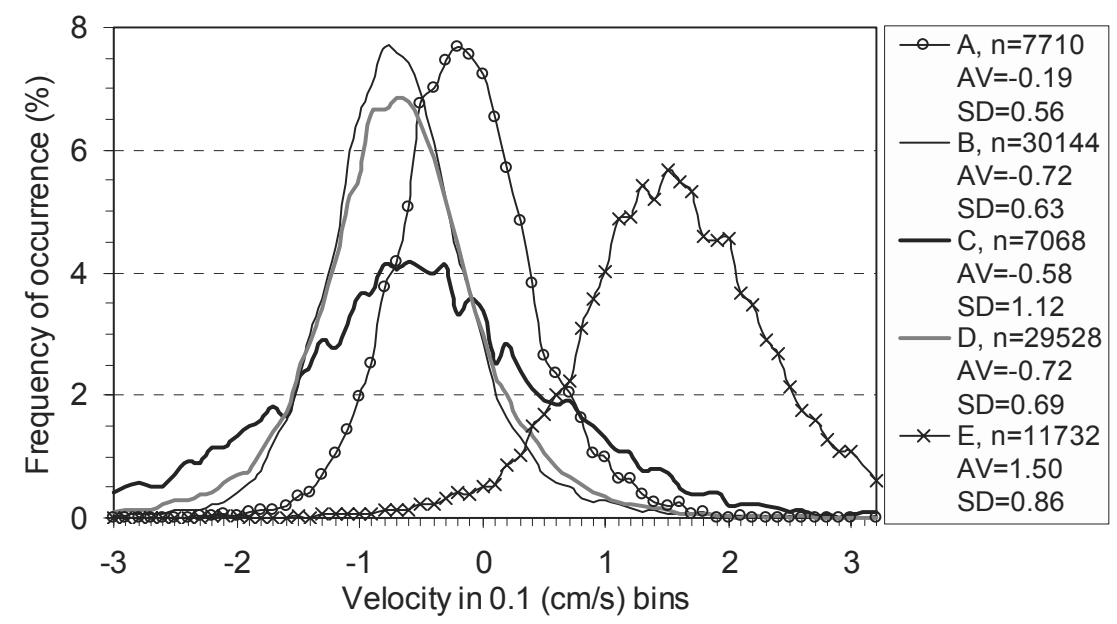

Figure 2: Histograms and statistics (n-count, AV-average, SD-st. deviation) of the vertical velocity data grouped by moorings (see Table 1). 
The corresponding smoothed spectra remained mostly between the confidence intervals of the white noise spectrum line (Fig. 5b). Perhaps only the low-frequency region of spectra (say, periods less than $1 \mathrm{cpd}$, but also depending on data set) reflected certain "meaningful" variations. In case of short series, they may appear as bias or trend (Fig. $4 \mathrm{abc}$ ), but in longer series they may represent several periods (Fig. 6b), which sources should be identified.

\subsection{Possible sources of variability}

Behind the white noise zone of the spectra, there may be various noise and error components. The vertical velocity component is much more sensitive than the horizontal component to biases inherent in the measuring process itself, such as errors in the instrument tilt angels, and spatial inhomogeneity of the flow field.

As the acoustic beams spread with height, they sample different water parcels, and inhomogeneity of the flow can introduce errors in data output. The water motions must be of a large scale compared to the separation of the beams and length of the pulse. Compared to the measurement integration period (depending on instrument set-up 2-4 minutes in burst mode), the scale of orbital motions of surface waves are too small and cannot be resolved, just adding some noise. Also, the influence of some other true small-scale hydrodynamic processes, such as Langmuir circulation, convective fluxes and turbulence can be substantial.

Langmuir circulation has probably the largest role in upper layer mixing. It is a wind driven helix circulation with the axis almost parallel to the wind. Nearly alongwind-aligned regular strikes or windrows mark surface convergence zones of the circulation cells, as they gather foam, buoyant algae or newly precipitated snow. The horizontal (crosswind) spacing of the Langmuir process is around 15$200 \mathrm{~m}$ and both upward and downward vertical velocities may reach about 30 $\mathrm{cm} / \mathrm{s}$ in the nearly regular vortex cells $[5,6]$.

a)
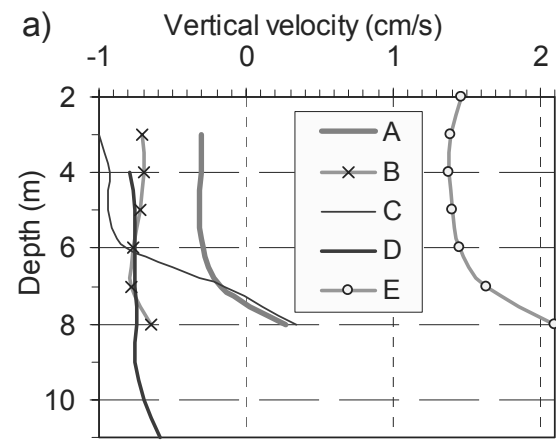

b) Standard deviation $(\mathrm{cm} / \mathrm{s})$

\section{2}

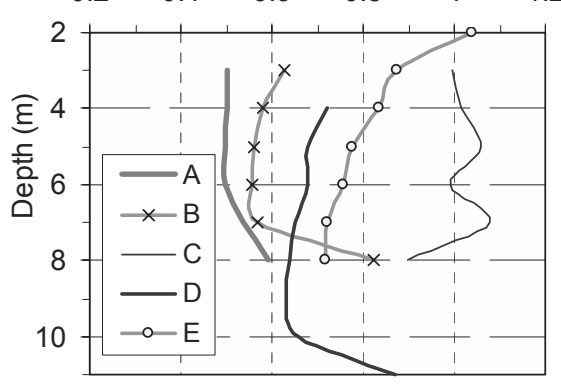

Figure 3: Vertical distributions of vertical velocities (a) and corresponding standard deviations (b) averaged over expeditions (see Table 1). 
The vertical velocities are larger in the sub-surface layer, but the vertical extension of the process is, depending also on age, a score of meters. The cells somewhat amalgamate and meander in space and time. Therefore, while during one measurement the flow situation may be more or less constant (yielding predominantly either upward or downward velocities), the different measurements likely fall in different parts of the cells and the vertical velocity readings can be quite different from each other. In our opinion, this can be one of the major sources of the noise in RDCP data. Although downward velocities are larger than upward velocities in the Langmuir cells, the corresponding spatial extension of these zones are reciprocal and no systematic component should appear over longer periods of time in a fixed marine point.
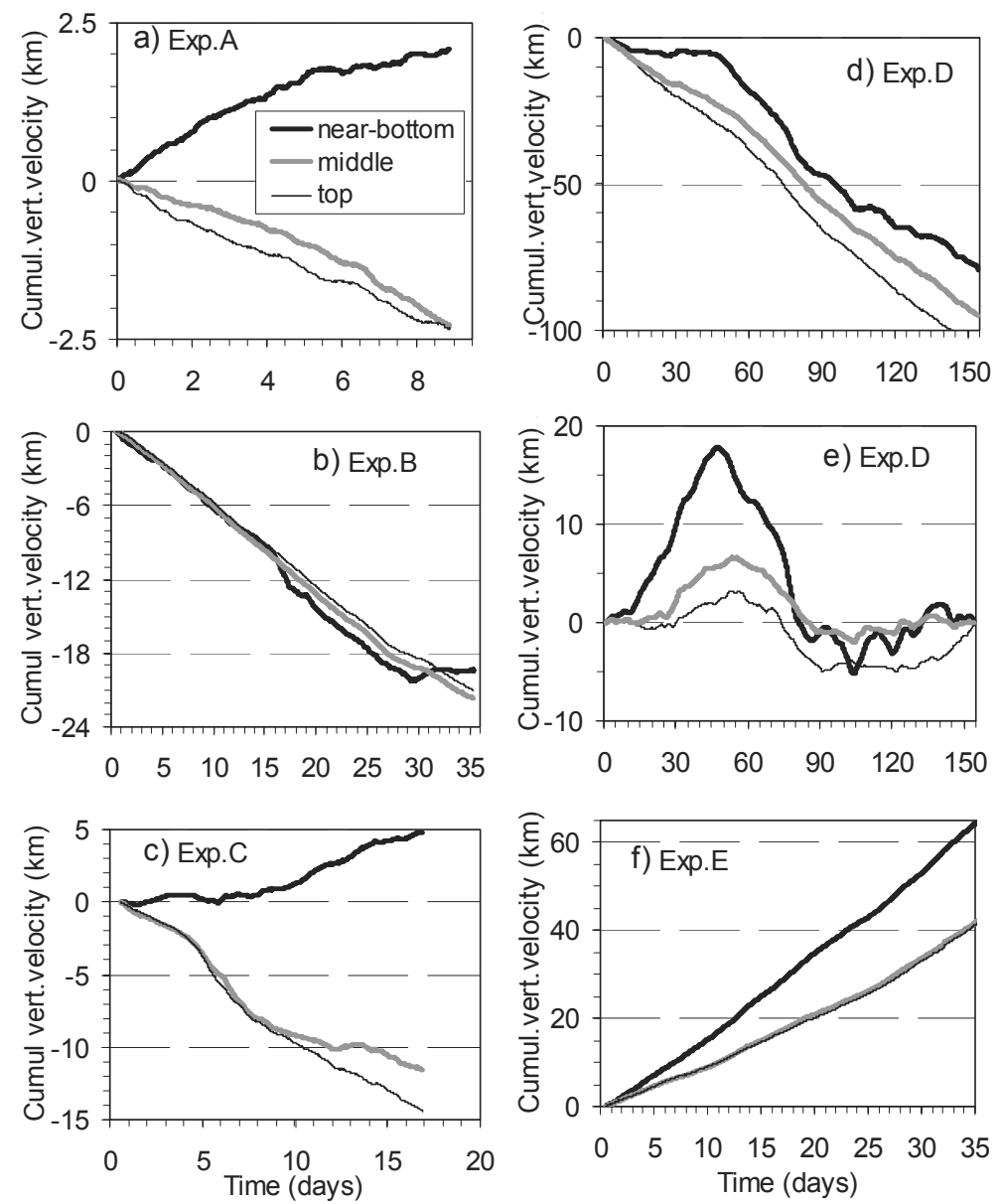

Figure 4: Integral curves of vertical velocities in near-bottom, middle and near-surface layers. Integral curves of the de-trended series (e). 


\subsection{Role of true hydrodynamic processes and movements of scatterers}

Although our deployments located above gentle nearshore bottom slopes, where up- and downwelling or upsloping could occur, it was impossible to explain the surprisingly large (order of $1 \mathrm{~cm} / \mathrm{s}$ ) systematic or quasiperiodic components by true hydrodynamic processes. The known physical sources of vertical velocities associated with large- or mesoscale dynamics (i.e. upwelling, fronts, eddies) contribute together about $0.1 \mathrm{~cm} / \mathrm{s}$, at most [7,8]. Vertical component due to sea level variations (see also Table 1) is of order $0.002 \mathrm{~cm} / \mathrm{s}$ and due to irregularities of local bottom topography or shoreline below $0.08 \mathrm{~cm} / \mathrm{s}$. Vertical velocities of Ekman pumping (upwelling) estimated from continuity equations are of order $0.01-0.1 \mathrm{~cm} / \mathrm{s}$. There may be larger vertical velocities, e.g. in some macrotidal narrow estuaries, though [9]. The magnitude seems to be also scale-dependent. Smaller scale processes may include larger velocity values, but they cannot be resolved by the RDCP, thus contributing mainly with noise.
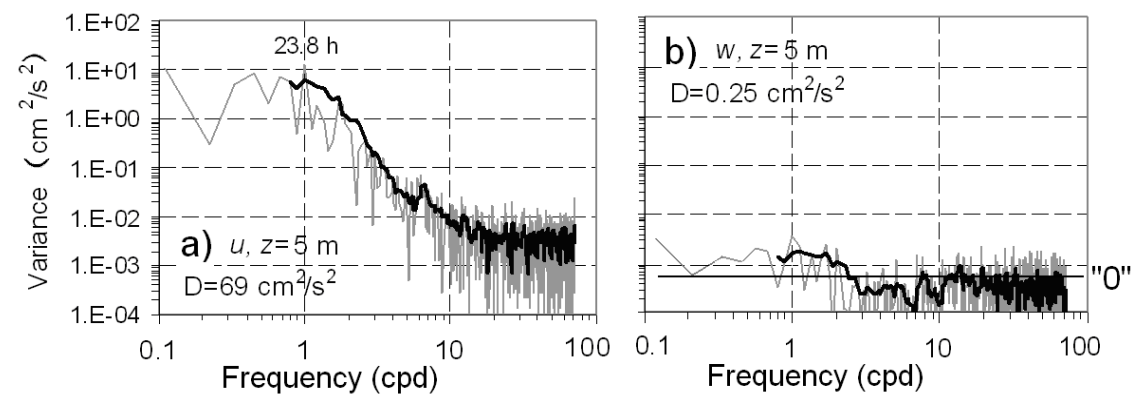

Figure 5: Examples of Fourier spectra of a horizontal (a) and vertical (b) velocity component (Exp.A). Frequencies in cycles per day (cpd). Smoothed over 7 periods values are shown with bold lines, the position of the white noise spectrum is shown with " 0 " in (b).

During at least two expeditions (B,E), the instrument was actually recording during and within the occurring upwelling, which was confirmed both by MODIS satellite imagery [2] and in situ measurement data (Fig. 7; [2]).

Typically for upwelling, rise in pycnocline and baroclinic alongshore jet with horizontal scale close to local internal Rossby radius [1] and near-surface velocities up to $60 \mathrm{~cm} / \mathrm{s}$ (Fig. 7bd) occurred in mild (3-6 m/s) easterly winds. After the event, westerly $8-14 \mathrm{~m} / \mathrm{s}$ winds were capable of yielding a barotrophic current only up to $30 \mathrm{~cm} / \mathrm{s}$. In time series of vertical velocities, however, there were no statistical components that could be attributed to upwelling. Evidently, the vertical velocities in the process, which is understood as mesoscale upwelling, are below detection capacity of the instrument. In integral vertical velocity graphs, they may yield about $10 \mathrm{~m} /$ day (see Fig. 4). There was no evidence of small-scale near-shore "upsloping" either, as the integral curves of vertical and horizontal currents were not correlated to each other. 

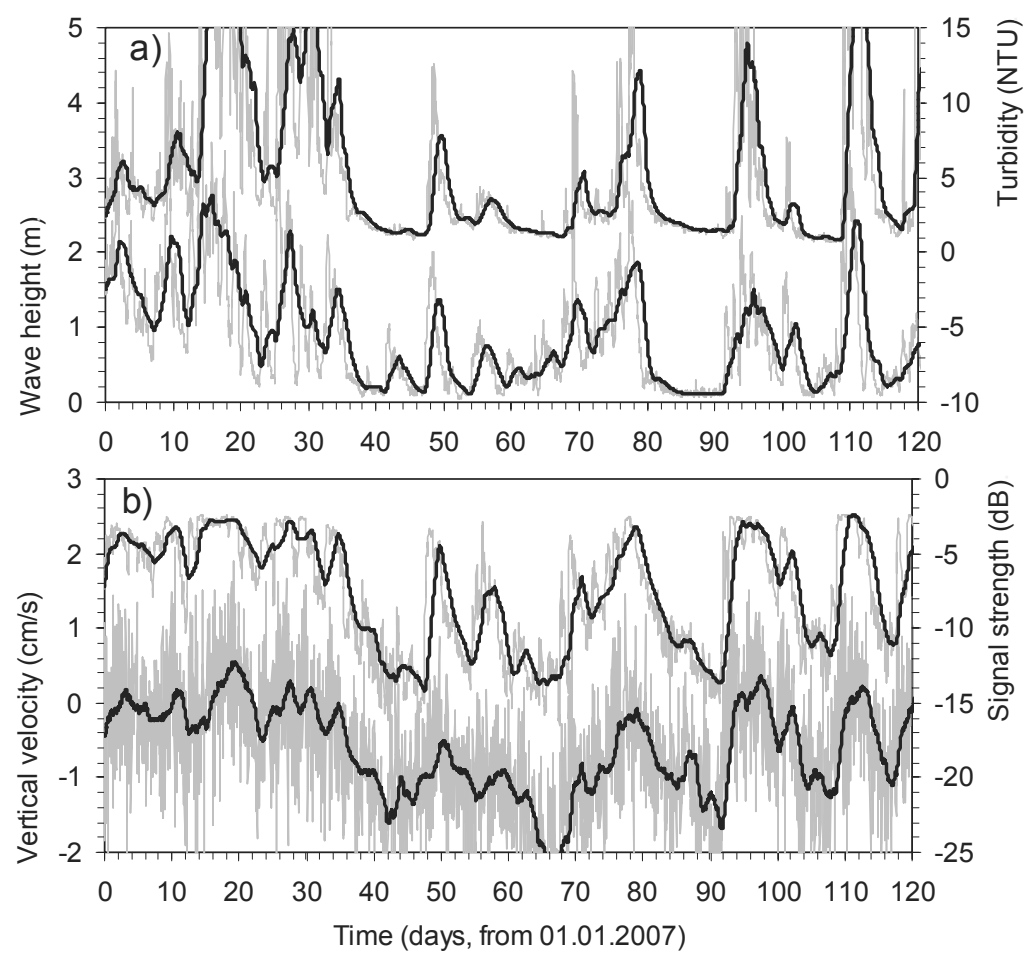

Figure 6: Variations in vertical velocity and backscattered signal strength (b) at $11 \mathrm{~m}$ depth, maximum wave heights and near-bottom turbidity (a) in Exp.D (excerpt): the original values (grey) and smoothed with 12 periods running averages (bold).

On the other hand, unusually high vertical velocities compared to those of "ordinary" models are suggested by experiences with non-hydrostatic 3D hydrodynamic models $[10,11]$, which perform differently in regions of sharply varying bathymetry.

The vertical velocity may be split into two contributions: whether an upwelling is induced by geometry of the domain, or by inherent upwelling mechanism. There seems to be a relationship between integral horizontal and vertical velocity components only in Exp.E (Fig. 6). However, keeping in mind the exceptionally high upward velocities (Fig. 2) during the particular mooring, the data and instrument conditions should be re-analysed after the retrieval of the instrument (moored until spring 2009 in location E). As the measured velocity components should be compensated internally for possible instrument tilts, the pronounced systematic component is difficult to explain. It seems like something has "boiled up", which can be, however, advectively brought to the location. There is also the possibility that the instrument was too close to the Kunda effluent pipe outlet. 
Finally, the Doppler-based technology presumes that scatterers flow ambiently with the water currents, but this is more or less valid only for horizontal motions. It is obvious, however, that a water column contains gas bubbles, suspended matter, detritus or small organisms that are not neutrally buoyant, or move up- or downward for some reason. Therefore, the resulted measured vertical velocity should appear as a weighted sum of the true water velocity and the influence of movements of scatterers. Indeed, a distinct dominant mechanism for vertical velocities was discovered in case D (Fig. 6). The vertical velocities were associated with wave height through the signal strength (i.e., strength of returning signal). The latter depends on the amount of scatterers in the water, and hence, also on turbidity. The correlations between both signal strength and vertical velocity ( $\mathrm{r}=0.64)$, as well as between turbidity and vertical velocity $(\mathrm{r}=0.44)$, were stronger in near-bottom layers. Smoothing of the series yielded stronger correlation (up to 0.8 , see also Fig. 6), but $r=0.44$ for the 3691 pairs of original near-bottom data is highly significant as well. Both turbidity and signal strength were more related to wave action and less to current speed [4].
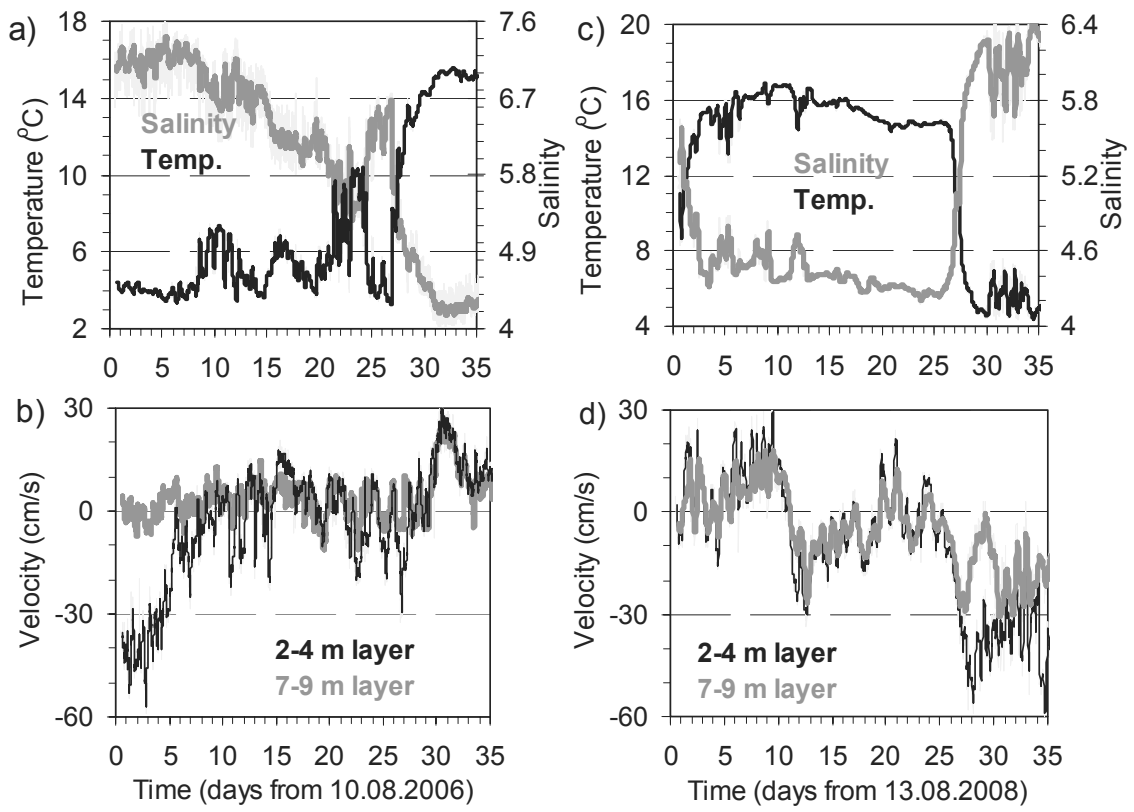

Figure 7: $\quad$ Upwelling-related variations in salinity and water temperature (a,c; upwelling conditions apply to low water temperature and high salinity) and alongshore current velocities at two depths (b,d) indicating near-surface coastal jets during expedition $2(\mathrm{a}, \mathrm{b})$ and 5 $(\mathrm{c}, \mathrm{d})$. 
During storm events, downward "vertical velocity" decreased or changed to upward flux, especially in the near-bottom layer (Fig. 6), while during calm periods, downward motions prevailed. Upon retrieving the instrument in May 2007, the mooring frame was covered by $20-30 \mathrm{~cm}$ of fine sand, confirming accumulative conditions to prevail in this hydrodynamically and geomporphically active location [4]. Thus, "vertical velocity" in such conditions clearly reflects the site- and time-dependent equilibrium between resuspension and sedimentation of mineral particles. The same mechanism was partially detectable also in case A (due to settling of material form nearby dredging and dumping sites) and $\mathrm{C}$ (during autumn storms).

This feature, upon careful planning of the experiment, can be used in quite surprising applications. For example, in specific conditions, such Doppler effectbased vertical velocity and signal strength data have been interpreted to detect movements of herring schools [12], diurnal vertical migrations of zooplankton [13], bubble release [14], but also in studies of sedimentation processes [4,15].

\section{Conclusions}

Vertical velocity may be caused both by true hydrodynamic processes, but also by movements of particles, which are not neutrally buoyant (suspended mineral particles, gas bubbles, detritus, marine organisms, etc.). Due to a mismatch of scales, the hydrodynamic processes contribute to the RDCP measurements with hardly detectable small values, or variations that can be described as "white noise" (e.g. in Langmuir circulation).

Apart from thermohaline and hydrochemical effects, upwelling manifests in the RDCP records through distinctive vertical structure of horizontal currents, and not by measurable vertical velocities. In certain geomorphically active, turbid nearshore zones of Estonia, vertical velocity reflects mainly equilibrium between resuspension and settling of mineral particles, which is mainly forced by wave activity.

\section{Acknowledgement}

The study was supported by the ESF through grant 7609 .

\section{References}

[1] Lehmann, A., Krauss, W. \& Hinrichsen, H.-H., Effects of remote and local atmospheric forcing on circulation and upwelling in the Baltic Sea. Tellus, 54A, pp. 299-316, 2002.

[2] Suursaar, Ü. \& Aps, R., Spatio-temporal variations of hydrophysical and chemical parameters during a major upwelling event in the southern coast of the Gulf of Finland in the summer of 2006. Oceanologia, 49, pp. 209$228,2007$. 
[3] Suursaar, Ü., Aps, R., Martin, G., Põllumäe, A. \& Kaljurand, K., Monitoring of the pulp mill effluents in the coastal waters of North Estonia. Water Pollution IX. (Series: WIT Transactions on Ecology and the Environment), D. Prats Rico \& C.A. Brebbia (Eds.), 111, pp. 217-226, 2008.

[4] Suursaar, Ü., Jaagus, J., Kont, A., Rivis, R. \& Tõnisson, H., Field observations on hydrodynamic and coastal geomorphic processes off Harilaid Peninsula (Baltic Sea) in winter and spring 2006-2007. Estuarine Coastal and Shelf Science, 80, pp. 31-41, 2008.

[5] Leibovich, S. \& Paolucci, S., The Langmuir circulation instability as a mixing mechanism in the upper ocean. Journal of Physical Oceanography, 10, pp. 186-207, 1980.

[6] Thorpe, S.A., Langmuir circulation. Annual Review of Fluid Mechanics, 36, pp. 55-79, 2004.

[7] Giordani, H., Prieur, L. \& Caniaux, G., Advanced insight into sources of vertical velocity in the ocean. Ocean Dynamics, 56, pp. 513-524, 2006.

[8] Luettich, R.A., Muccino, J.C. \& Foreman, M.G.G., Considerations in the Calculation of Vertical Velocity in three-Dimensional Circulation Models, Journal of Atmospheric and Oceanic Technology, 19, pp. 2063-2076, 2002.

[9] Wewetzer, S.F.K., Duck, R.W. \& Anderson, J.M., Acoustic Doppler current profiler measurements in coastal and estuarine environments: examples from the Tay Estuary, Scotland. Geomorphology, 29, pp. 21-30, 1999.

[10] Kanarska, Y. \& Maderich, V., A non-hydrostatic numerical model for calculating free-surface stratified flows. Ocean Dynamics, 53, pp. 176-185, 2003.

[11] Deleersnijder, E., Upwelling and upsloping in three-dimensional marine models. Applied Mathematical Modelling, 13, pp. 462-467, 1989.

[12] Zedel, L., Knutsen, T. \& Patro, R., Acoustic Doppler current profiler observations of herring movement. ICES Journal of Marine Science, 60, pp. 846-859, 2003.

[13] Ott, M.W., The accuracy of acoustic vertical velocity measurements: instrument biases and the effect of Zooplankton migration. Continental Shelf Research, 25, pp. 243-257, 2005.

[14] Greinert, J., Monitoring temporal variability of bubble release at steeps: The hydroacoustic swath system GasQuant. Journal of Geophysical Research, 113, C07048, doi:10.1029/2007JC004704, 2008.

[15] Merckelbach, L.M. \& Ridderinkhof, H., Estimating suspended sediment concentration using backscatterance from acoustic Doppler profiling current meter at a site with strong tidal currents. Ocean Dynamics, 56, pp. 153-168, 2006. 